\title{
EVALUATION OF THE ESFR END OF CYCLE STATE AND DETAILED ANALYSIS OF SPATIAL DISTRIBUTIONS OF REACTIVITY COEFFICIENTS
}

\author{
Una Davies ${ }^{1}$, Marat Margulis ${ }^{1}$, Eugene Shwageraus ${ }^{1}$, Emil Fridman ${ }^{2}$, Nuria \\ Garcia-Herranz ${ }^{3}$, Antonio Jimenez-Carrascosa ${ }^{3}$, Oscar Cabellos ${ }^{3}$, Robbie Gregg ${ }^{4}$ and Jiri \\ Krepel $^{5}$ \\ ${ }^{1}$ University of Cambridge, United Kingdom \\ ${ }^{2}$ Helmholtz-Zentrum Dresden Rosendorf, Germany \\ ${ }^{3}$ Universidad Politecnica de Madrid, Spain \\ ${ }^{4}$ National Nuclear Laboratory, United Kingdom \\ ${ }^{5}$ Paul Scherrer Institute, Switzerland
}

\begin{abstract}
The ESFR-SMART project is the latest iteration of research into the behaviour of a commercial-size SFR core throughout its lifetime. As part of this project the ESFR core has been modelled by a range of different reactor physics simulation codes at its end of cycle state, and the important safety relevant parameters evaluated. These parameters are found to agree well between the different codes, giving good confidence in the results.

A detailed mapping of the local sodium void worth is also performed due to the problems associated with the positive void coefficient seen in large SFR designs. The local void worth maps show that the use of zone-wise coefficients replicates the important reactivity feedbacks to a high degree, indicating their suitability for use in SFR simulations.
\end{abstract}

KEYWORDS: ESFR, sodium-cooled fast reactor, spatial reactivity coefficients, sodium void worth

\section{INTRODUCTION}

The European Sodium-cooled Fast Reactor (ESFR) is a concept for a commercial-size 3600 MWth SFR which has been the focus of a number of European Horizon 2020 ventures, the most recent of which is the ESFR-SMART project [1]. This new reactor aims to be capable of reprocessing both its own and legacy waste; to be more reliable, environmentally-friendly, and affordable in operation; and to better protect against nuclear proliferation. Furthermore, the ESFR aims to be demonstrably safer than previously operated LWRs and SFRs. This ambitious safety goal is supported through analysis carried out in the Horizon 2020 project, ESFR Safety Measures Assessment and Research Tools (ESFR-SMART).

This paper will present an overview of the results of the ESFR-SMART Task 1.2.2, evaluating the safety and performance neutronic parameters of the ESFR core at the end of cycle (EOC). The most conservative EOC state has been selected to be modelled in a series of initial benchmark calculations, including criticality and rod worths, zone-wise Doppler constant, void reactivity, and 
a selection of expansion coefficients. Detailed mapping of the global and local sodium void reactivity effects within the ESFR core at its EOC state was also carried out. These parameters are of particular importance due to the positive sodium void coefficient observed in large SFRs and the spatial dependence of the sodium voiding effect between different regions of the core. The maps will provide more information about the spatial distribution of these coefficients and their linearity and spatial correlations, as well as informing the applicability of the zone-wise coefficients for transient analysis based on point kinetics. This will contribute to safety and performance assessments of the ESFR core at its EOC stage and will support the project aims of demonstrating improved safety characteristics, as well as supporting the verification of reactor physics simulation methods for SFR applications.

This task was led by the Nuclear Energy Research Group at the University of Cambridge, who generated the Serpent reference results presented in this paper with the help of the Helmholtz-Zentrum Dresden Rosendorf. The supporting participants of the task were the Universidad Politecnica de Madrid, using KENO-VI; the UK National Nuclear Laboratory, using WIMS; and the Paul Scherrer Institute, using ERANOS 2.

\section{METHODOLOGY}

In the first part of this work, the fuel cycle and safety relevant parameters of the ESFR-SMART core design at its EOC state were evaluated by all participants. This included criticality, control rod worths, and zone-wise analysis of reactivity coefficients. Following this, a more detailed spatial mapping of the sodium void worth in the ESFR core was performed.

\subsection{ESFR EOC core description}

The ESFR core parameters have been described in detail elsewhere [2] and so are omitted here for the sake of brevity. In its EOC state, the ESFR core has been burned for 2100 days at full power with a six-batch refuelling scheme. This depletion calculation was performed in the previous ESFR-SMART project task (1.2.2) using Serpent, providing the detailed spatially-dependent fuel compositions used in this task.

\subsection{Fuel cycle and safety relevant parameters at EOC}

The total control rod worth as a function of rod insertion was evaluated and plotted in an S-curve. All rod banks were moved together for these calculations, with incremental insertions of $12 \mathrm{~cm}$.

For the Doppler calculations, the core was split up into inner fuel, outer fuel, and fertile blanket. Calculations were performed in each of these regions for low, intermediate, and high fuel temperatures.

For the sodium void worth calculations the different voiding zones considered are shown in Fig. 1. An additional five configurations ( $6-10)$ were added to those considered in the previous task (1 - 5) [3] evaluating the core at the beginning of life (BOL), in order to account for the breeding of new fissile materials in the blanket regions. The first five are compared with their BOL values to evaluate the change in the void worth due to burnup . 


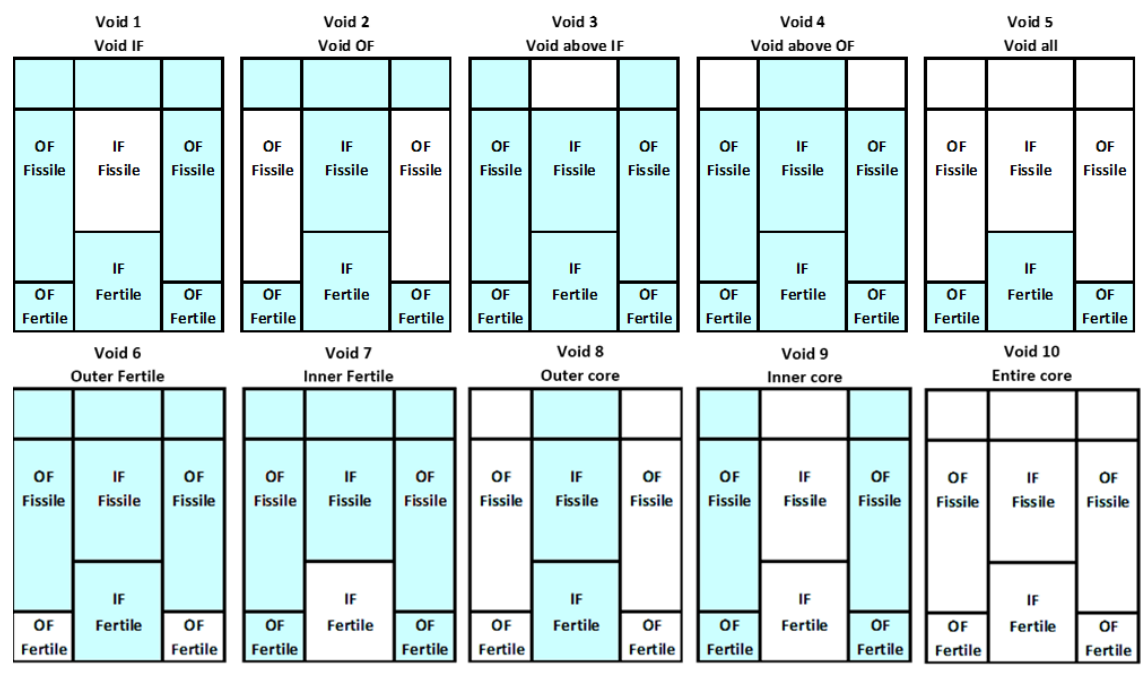

Figure 1: Sodium void zones and corresponding case numbers

Thermal expansion coefficients were calculated to investigate the impact of material expansion in difference core zones. The results were estimated based on the variation in temperature $(\mathrm{pcm} / \mathrm{K})$ and the variation in length $(\mathrm{pcm} / \mathrm{cm})$.

\subsection{Detailed mapping core decomposition}

In the second part of this work the local sodium void worth was calculated on a finer spatial mesh as shown below in Fig. 2. Radially, the assemblies were separated into five cooling groups, while axially the fertile, fissile, and plenum regions of the fuel assemblies were separated into thinner layers as shown. Sodium was then voided in each node separately and the local sodium void worth calculated.

\subsection{Participant codes}

WIMS is a deterministic reactor physics code developed by the ANSWERS team at Wood Nuclear [4]. The 3D diffusion solver MERLIN has been used for this work with assembly-homogenised cross sections generated using the WIMSECCO fine-group starting module and the CACTUS method of characteristics sub-solver. The superhomogenisation method [5] is used to correct the control rod homogenised cross sections. WIMS treats unresolved resonances using resonance integrals in the equivalence theory method and used the JEFF3.1.2 nuclear data library.

KENO-VI is the three-dimensional Monte Carlo criticality module of SCALE Code System [6], developed and maintained by Oak Ridge National Laboratory. In this work, calculations are performed using the JEFF-3.1 based AMPX-formatted nuclear data library processed at UPM. It is important to note that probability tables are switched off for this work due to the issue related to the treatment carried out by AMPX in the unresolved resonance range [7].

ERANOS 2 is an optimised deterministic calculation system [8] consisting form several mod- 

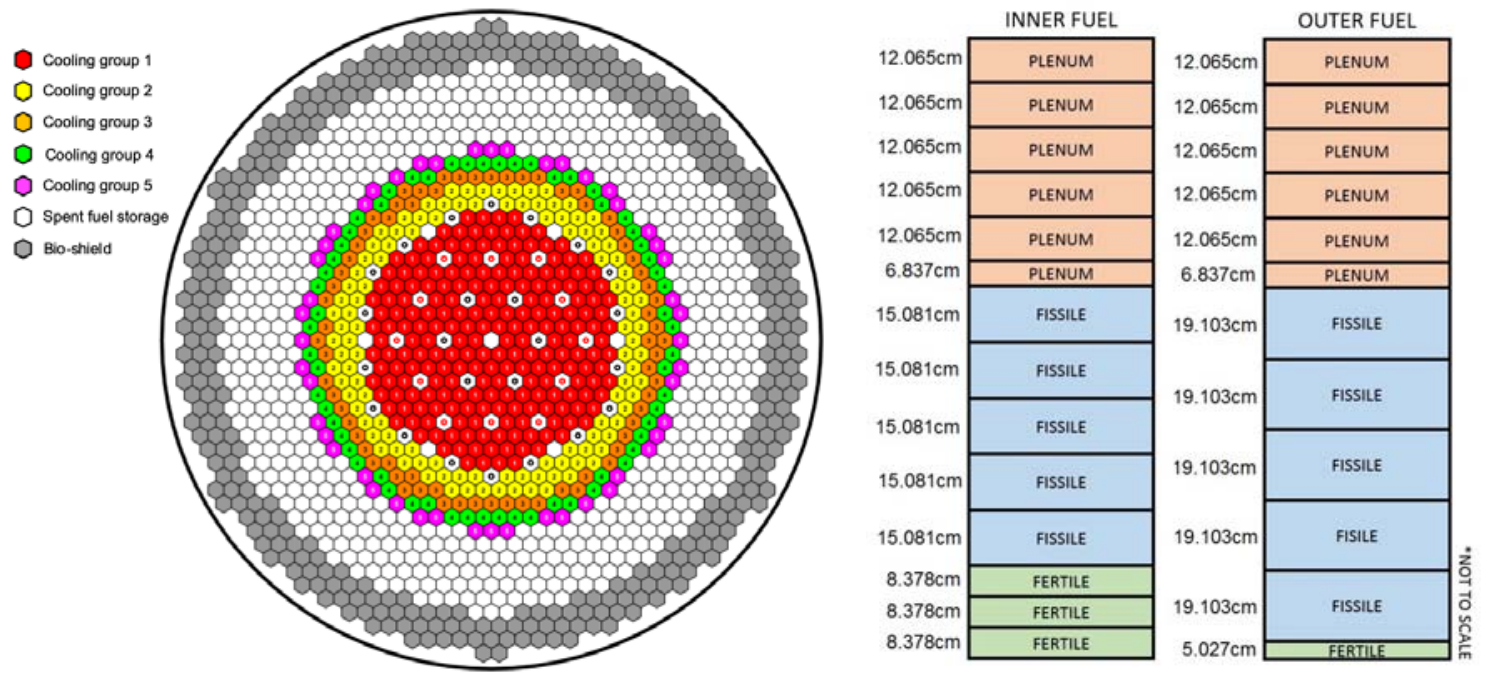

Figure 2: Radial mesh according to cooling group distribution and axial mesh layers

ules. The results presented in this paper were based on cell level cross-section calculation with ECCO module using standard calculation route passing through 1968 energy group step and using JEFF3.1 cross-section library. The hexagonal-z flux calculation was accomplished with nodal variational transport module VARIANT using 33 neutron group structure. Compared to other codes, the burnup fuel distribution at EOC state was obtained also by ERANOS simulation using the EQL3D procedure [9] to simulate the reactor batch-wise operation.

Serpent is a Monte Carlo code developed by the VTT institute in Finland [10]. It has been used extensively throughout the ESFR-SMART project [11] [12] to provide fully heterogeneous benchmark models to which other results may be compared. In this work the JEFF3.1 nuclear data library was used.

Serpent allows the user to specify an option to sample unresolved resonances from probability tables during the calculation. While this does increase the calculation time, it improves the accuracy of the results. Due to the different methods of treating unresolved resonances in KENO-VI and WIMS, two calculations were performed with this option switched 'on' and 'off'.

\section{RESULTS}

\subsection{Fuel cycle and safety relevant parameters at EOC}

\subsubsection{EOC criticality}

The results for the criticality at EOC in the form of the effective multiplication factor with all rods withdrawn are shown in Table 1.

The agreement between Serpent and KENO-VI is good, with the two codes within $17 \mathrm{pcm}$ when the use of probability tables is turned off in Serpent. WIMS also agrees with Serpent to within 242 
Table 1: Initial k-effective results

\begin{tabular}{|l|c|c|}
\hline Code & K-effective & Std dev \\
\hline Serpent (with URES) & 1.00421 & $1 \times 10^{-5}$ \\
\hline Serpent (without URES) & 1.00403 & $1 \times 10^{-5}$ \\
\hline KENO-VI & 1.00420 & $5 \times 10^{-5}$ \\
\hline WIMS & 1.00645 & N/A \\
\hline
\end{tabular}

pcm, which is deemed an acceptable discrepancy between deterministic and Monte Carlo codes.

\subsubsection{Control rod worths}

The results for the control rod insertions are shown in Fig. 3. The Serpent and KENO-VI results show a good agreement with a small consistent difference, whereas the difference between the WIMS results and the Serpent benchmark becomes less as the rods are inserted. This could indicate a slight underestimation of the control rod worth, but as the difference is below $150 \mathrm{pcm}$ this is not deemed significant for a comparison between deterministic and Monte Carlo codes.
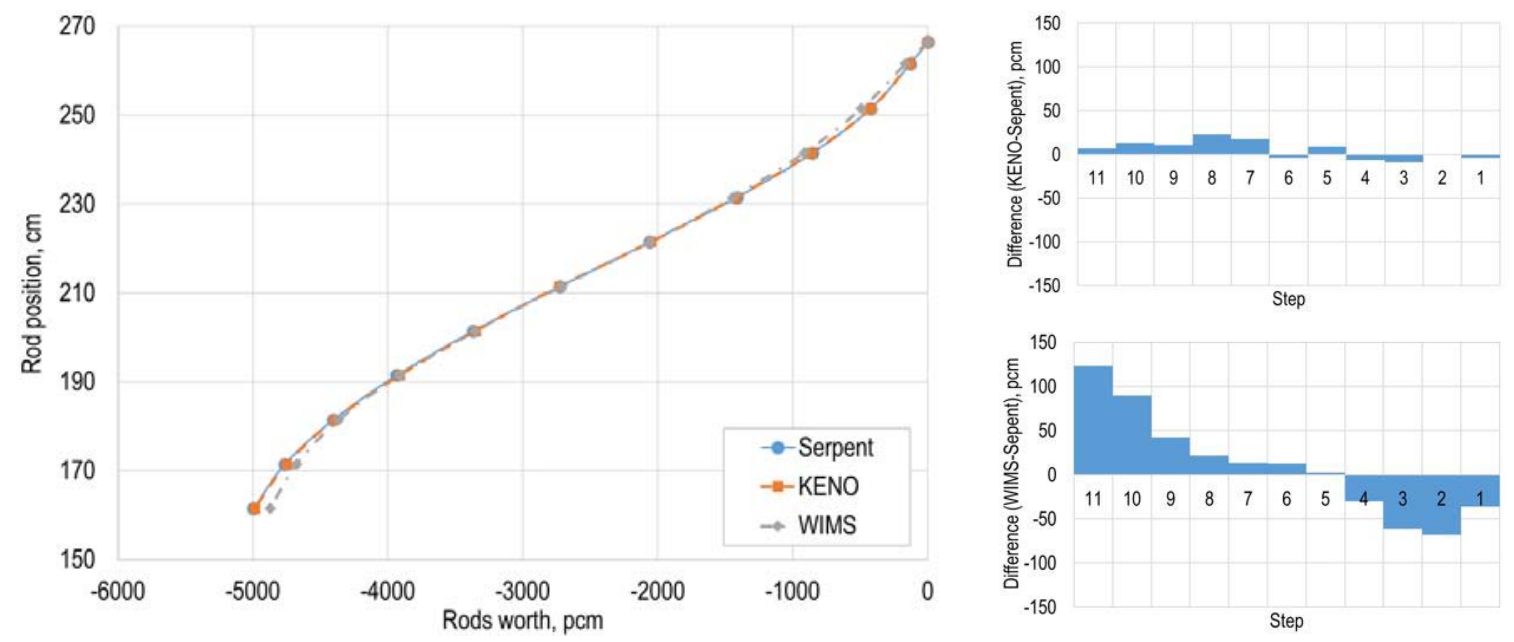

Figure 3: Control rod worths and differences between KENO-VI/WIMS and Serpent

\subsubsection{Doppler constants}

The results for the Doppler calculations are shown in Fig. 4. The first result in each section (Cases 1, 4, and 7) refers to the inner fuel (excluding the fertile blanket), the second result (Cases 2, 5, and 8 ) refers to the outer fuel (also excluding the fertile blanket), and the third results (Cases 3, 6, and 12) refers to all fertile blanket zones in both the inner and the outer fuel regions. 


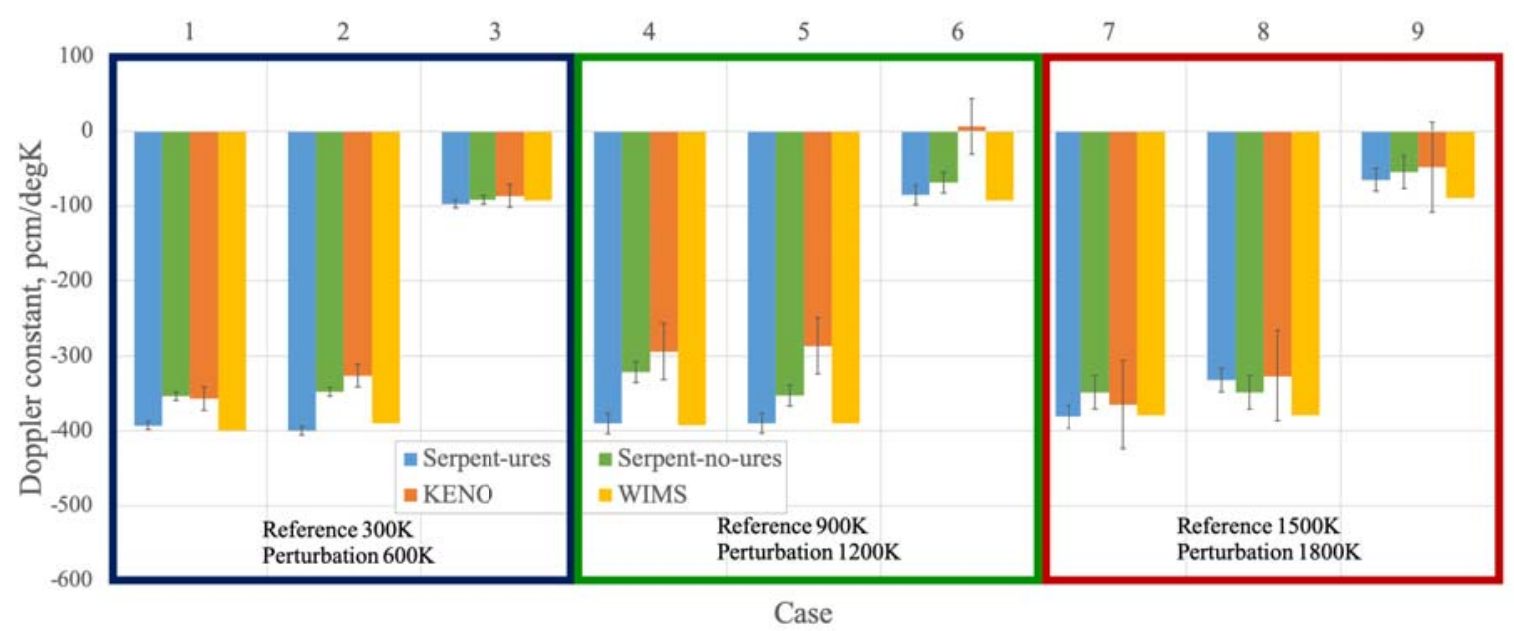

Figure 4: Doppler results

The Serpent and KENO-VI results show a good general agreement, which improves as expected when the use of probability tables for unresolved resonances is disabled in Serpent. The WIMS results agree with Serpent to within $250 \mathrm{pcm}$.

\subsubsection{Thermal expansion reactivity}

The results for the thermal expansion coefficients are shown in Fig. 5. The cases are identified as follows:

Cases $1 \& 2$ : Axial fuel expansion of the fissile and fertile parts of the inner/outer core

Cases $3 \&$ 4: Axial cladding expansion in the inner/outer core

Cases 5 \& 6: Radial cladding expansion in the inner/outer core

Case 7: Diagrid expansion

It should be noted that all Serpent calculations were performed with the resonance probability tables.

The Serpent and KENO-VI results show a generally good agreement, while the WIMS and ERANOS results do show some deviation from the Monte Carlo codes. The cause of this deviation is currently under investigation but the effects under consideration are very small.

\subsubsection{Sodium void reactivity}

The results for the sodium void reactivity calculations are shown in Fig. 6. The case numbers correspond to the different scenarios shown in Fig. 1. 

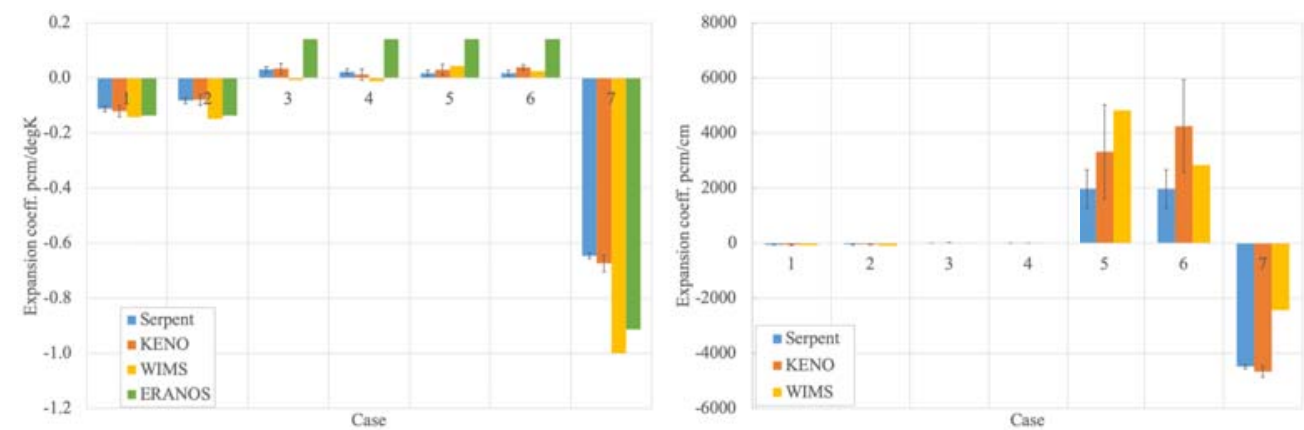

Figure 5: Thermal expansion results

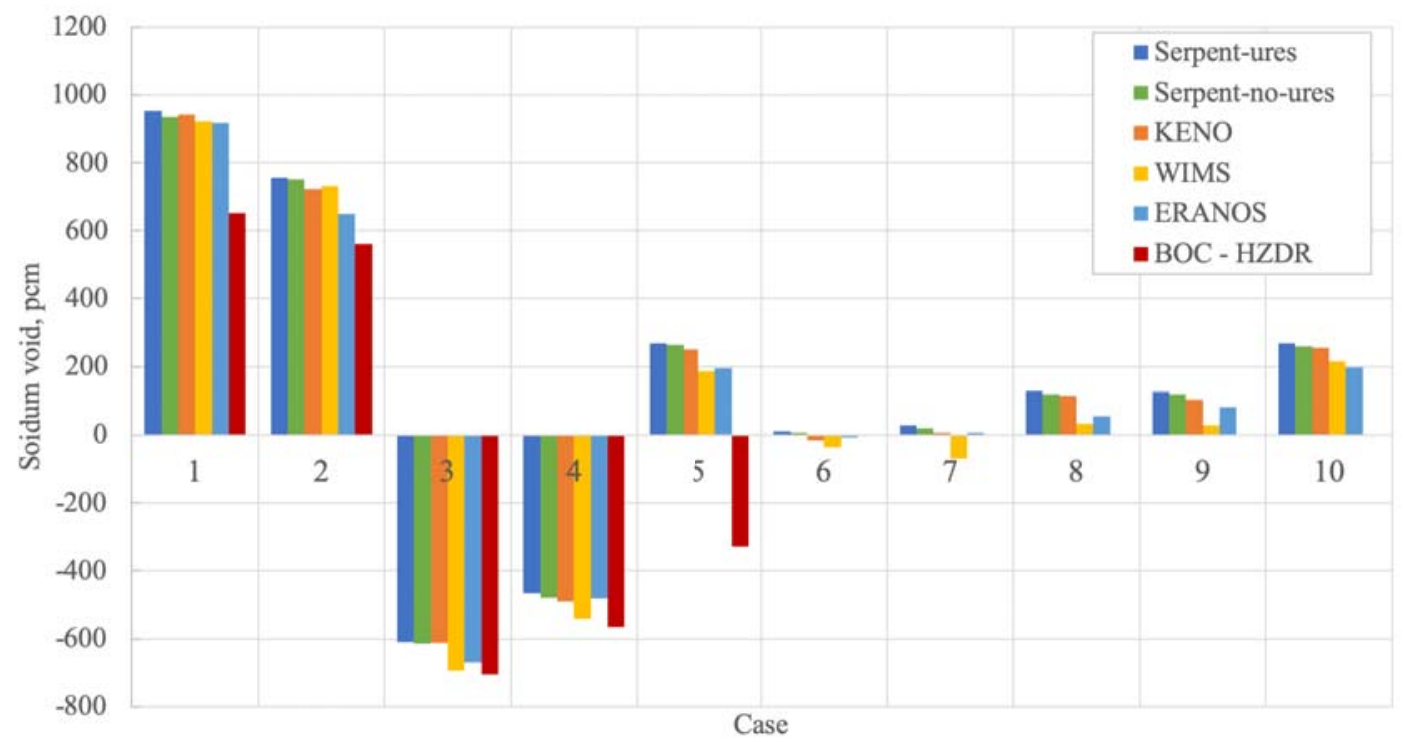

Figure 6: Sodium void effect results

A good agreement is seen between Serpent, KENO-VI, WIMS, and ERANOS. The main differences are small and are seen in cases involving voiding of the fertile zones, which are of less importance to reactor safety.

When compared to the HZDR Serpent BOL results, the sodium void effect can be seen to become more positive over time in all regions. This is particularly noticeable in Case 5, where the fissile and plena regions in the inner and outer fuel zones are voided. This is due to the breeding of plutonium in the fuel.

Fig. 7 shows that in every fuel batch except Batch 1, the amount of plutonium in the inner fuel increases. A similar trend is seen in the outer fuel. This increase in plutonium in the fissile fuel results in a higher sodium void worth in the fuelled regions due to the greater amount of fissile material present compared with the BOL state. 


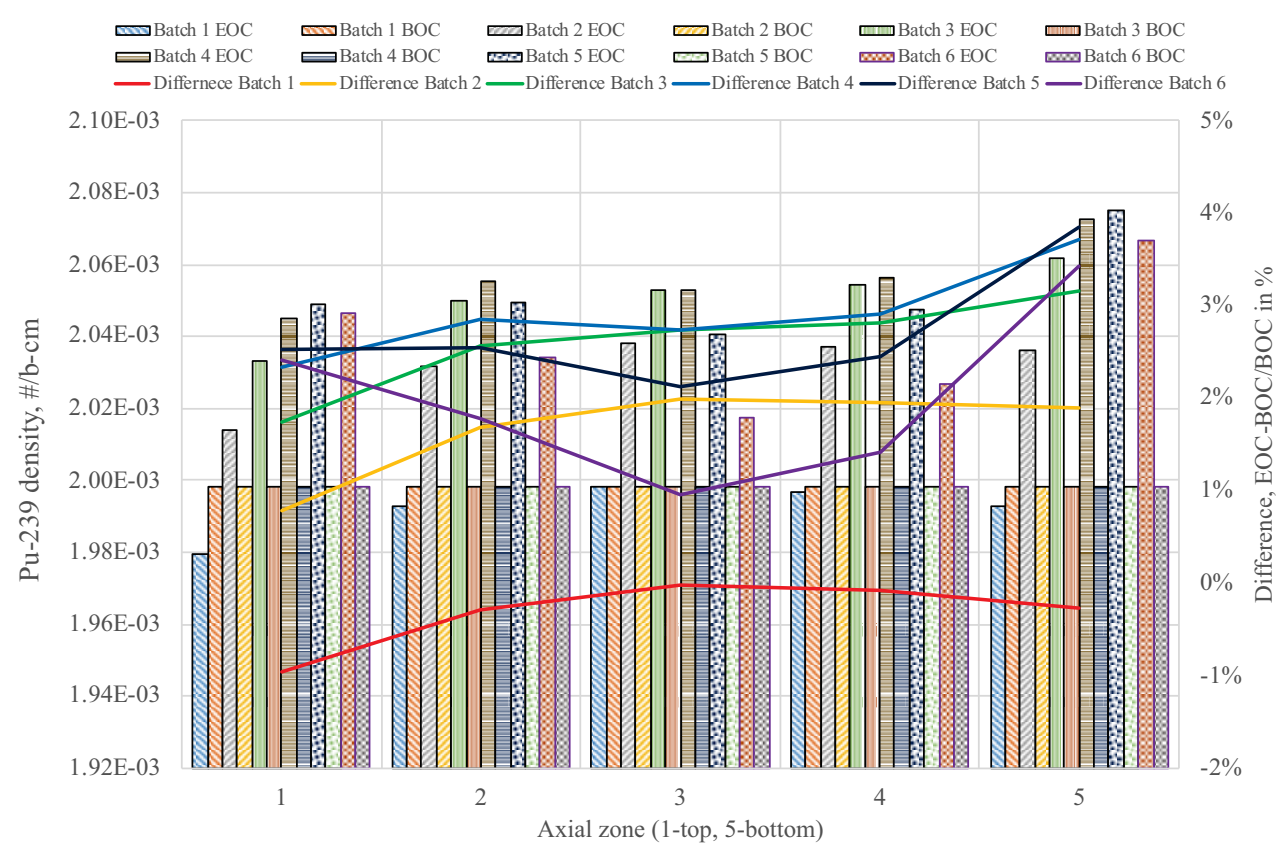

Figure 7: Plutonium concentration in inner fuel compared with BOL

\subsection{Detailed spatial resolution of the sodium void coefficient}

To calculate the local coefficients, the ESFR core was split up into a finer spatial mesh according to the zones shown in Fig. 1. The sodium void worth was then evaluated at the centre of each node. The results calculated by Serpent (with the resonance probability tables used) are shown in Fig. 8.

It can be seen that the sodium void worth is the most positive in the centre of the active core region, and the most negative in the plenum region. The effect is most pronounced in the inner core assemblies closer to the centre, with the cooling groups further to the edge of the core exhibiting the same trend with a smaller magnitude.

This is consistent with expectations. In the centre of the core, voiding of the sodium results in a removal of a prominent scattering cross section and a subsequent hardening of the neutron spectrum and increase in reactivity. In the plenum, voiding the sodium allows fewer neutrons to be scattered back into the core and results in more of them reaching the upper axial absorber positioned above the plenum, producing an increase in leakage and decrease in reactivity.

These spatial maps indicate that the zone-wise sodium void worths are an appropriate simplification of the more detailed correlations. In both cases the most positive area of sodium void worth is found in the centre of the inner fuel, while the effect of the plenum voiding is negative. 


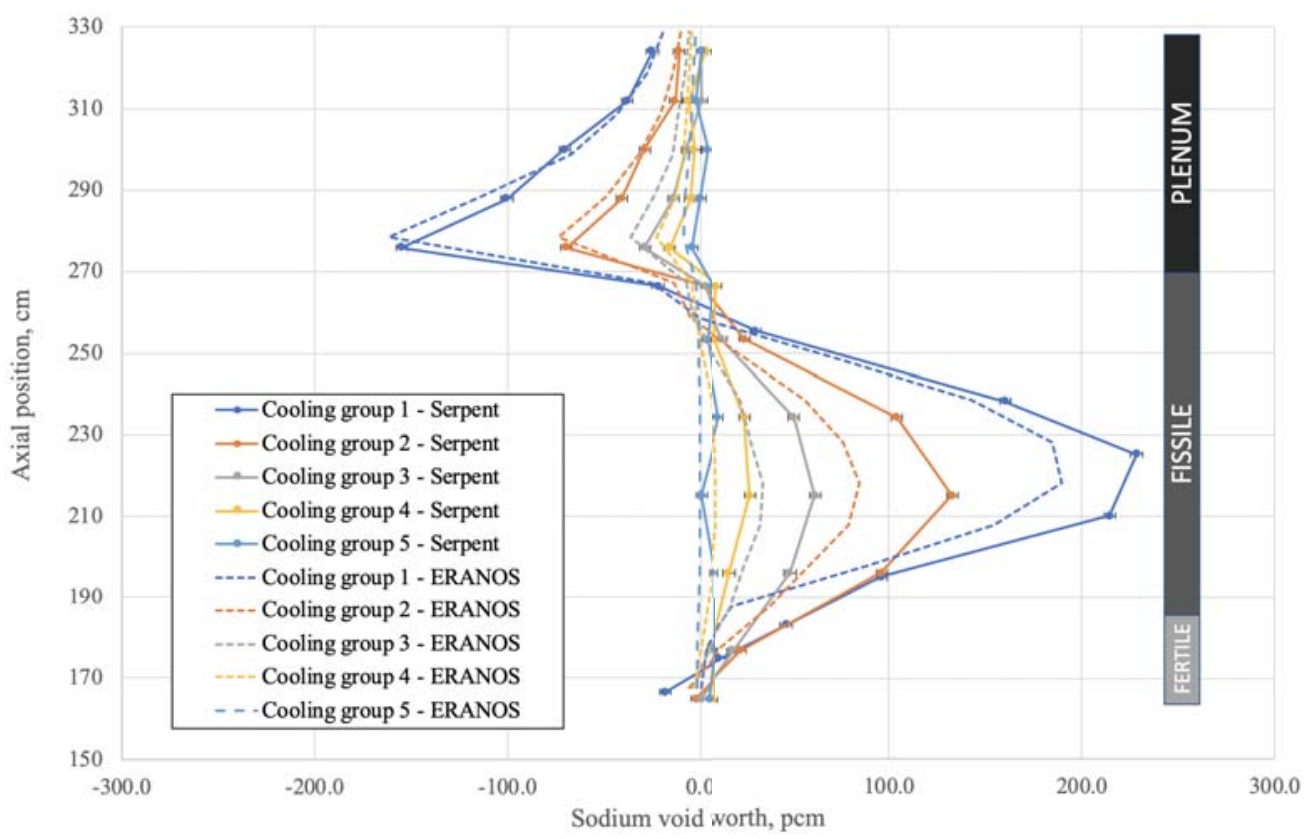

Figure 8: Local sodium void effect results

\section{CONCLUSIONS}

The ESFR core has been modelled in its EOC state. Calculations have been performed to determine the relevant fuel cycle and safety parameters, including initial criticality, control rod worths, and zone-wise analysis of reactivity coefficients. A satisfactory level of agreement is seen between Serpent, KENO-VI, WIMS, and ERANOS for these results. The sodium void worth is found to become more positive over time as a result of the breeding of plutonium in the fissile zones.

Investigations have also been performed into the local sodium void worths, using a finer spatial mesh than for the zone-wise calculation in order to evaluate the linearity and spatial correlations. These more detailed maps of the sodium void worths follow the same pattern as the results for the zone-wise calculations, indicating the suitability of the less detailed zone-wise coefficients for general use.

Future work is being carried out to quantify the uncertainty arising from the nuclear data in relation to the main safety relevant parameters, and to map the decay heat distribution in time and space. These further results will inform the additional transient calculations which are planned for the next stages of the ESFR-SMART project.

\section{ACKNOWLEDGEMENTS}

This work has been prepared within EU Project ESFR-SMART which has received funding from the EURATOM Research and Training Programme 2014-2018 under the Grant Agreement No. 754501. 


\section{REFERENCES}

[1] K. Mikityuk, E. Girardi, J. Krepel, E. Bubelis, E. Fridman, A. Rineiski, N. Girault, F. Payot, L. Buligins, G. Gerbeth, N. Chauvin, C. Latge, and J.-C. Garnier. "ESFR - SMART: new Horizon - 2020 project on SFR safety." In International Conference on Fast Reactors and Related Fuel Cycles: Next Generation Nuclear Systems for Sustainable Developmen. Yekaterinburg, Russia (2017).

[2] A. Rineiski, C. Meriot, M. Marchetti, J. Krepel, K. I. T. Iket, C. Nord, B. G. Monge, P. Scherrer, and I. Psi. "Core Safety Measures in Esfr-Smart." PHYSOR 2018: Reactor Physics Paving The Way Towards More Efficient Systems (2018).

[3] E. Fridman and K. Mikityuk. "ESFR T1.2.1 Vademecum.” Technical report (2019).

[4] B. Lindley, J. Hosking, P. Smith, D. Powney, B. Tollit, T. Newton, R. Perry, T. Ware, and P. Smith. "Current status of the reactor physics code WIMS and recent developments." $A n$ nals of Nuclear Energy, volume 102, pp. 148-157 (2017).

[5] A. Kavenoky. “The SPH homogenisation method." In A Specialists' Meeting on Homogenization Methods in Reactor Physics, IAEA TECDOC-231 (1978).

[6] B. T. Rearden and M. A. Jessee. "SCALE Code System." Technical report, Oak Ridge National Laboratory (ORNL), Oak Ridge, TN (United States) (2016).

[7] A. Jiménez-Carrascosa, E. Fridman, N. García-Herranz, F. Alvarez-Velarde, P. Romojaro, and F. Bostelmann. "About the impact of the Unresolved Resonance Region in Monte Carlo simulations of Sodium Fast Reactors." (2019).

[8] J. M. Ruggieri, J. Tommasi, J. F. Lebrat, C. Suteau, D. Plisson-Rieunier, C. De Saint Jean, G. Rimpault, and J. C. Sublet. "ERANOS 2.1: International code system for GEN IV fast reactor analysis." In Proceedings of the 2006 International Congress on Advances in Nuclear Power Plants, ICAPP'06 (2006).

[9] J. Krepel, S. Pelloni, K. Mikityuk, and P. Coddington. "EQL3D: ERANOS based equilibrium fuel cycle procedure for fast reactors." Annals of Nuclear Energy (2009).

[10] J. Leppänen, M. Pusa, T. Viitanen, V. Valtavirta, and T. Kaltiaisenaho. "The Serpent Monte Carlo code: Status, development and applications in 2013." Annals of Nuclear Energy, volume 82, pp. 142-150 (2015).

[11] A. Ponomarev, A. Bednarova, and K. Mikityuk. "New Sodium Fast Reactor Neutronics Benchmark." In PHYSOR 2018: Reactor Physics paving the way towards more efficient systems. Cancun, Mexico (2018).

[12] K. Mikityuk, E. Girardi, J. Krepel, E. Bubelis, E. Fridman, A. Rineiski, N. Girault, F. Payot, L. Buligins, G. Gerbeth, N. Chauvin, C. Latge, and J. Guidez. "Horizon-2020 ESFR-SMART project on SFR safety: status after first 15 months.” (2019). 